\title{
Migration of a fractured inferior vena cava filter strut to the right ventricle of the heart: a case report
}

\author{
Hani Shennib ${ }^{1 *}$, Bradley Bowles ${ }^{2}$ and Kelli Hickle ${ }^{2}$
}

\begin{abstract}
A 23 year old woman presented with sudden onset retrosternal chest pain following an attempt to move a heavy object from her vehicle. Multiple fractured struts of an inferior vena cava filter were identified in the distal right and left pulmonary artery branches, and in the free wall of the right ventricle. A small pericardial effusion was noted. Because of the depth of penetration into the right ventricle, it was perceived not to be amenable to endovascular retrieval. Over several days of observation, she continued to have progressive retrosternal and left shoulder pain. She underwent exploratory sternotomy and extraction of a strut that was partially protruding from the right ventricle and abrading the diaphragmatic pericardium. The patient recovered quite well and was discharged on the third postoperative day.
\end{abstract}

Keywords: IVC filter migration, IVC filter fracture, Bard Recovery, Pericardial effusion, Ventricular perforation

\section{Background}

Migration of fragments is a known complication of inferior vena cava (IVC) filter placement. Fragments that migrate to the right side of the heart can further lodge in the right ventricular wall or may migrate further into the pulmonary arteries. Right ventricular wall implantation can progress to penetration, hemopericardium, tamponade and possible death. Management of an IVC fragment which migrates into the right ventricle can be challenging. There are neither clear guidelines nor sufficient literature of how to best manage and treat such complex situations.

We present a case of IVC filter fracture and migration into the right ventricle which was treated with sternotomy and extraction of the fragment from its free wall.

\section{Case presentation}

Our patient is a 23 year old Caucasian female who presented to the emergency department complaining of severe, sharp mid-chest pain that increased with inspiration. The patient stated that the pain started while she was

\footnotetext{
* Correspondence: hanishennib@email.com

'Arizona Heart Hospital, 1930 East Thomas Road, Phoenix, AZ 85016, USA Full list of author information is available at the end of the article
}

lifting a stroller and stooping to prepare a vehicle seat for her four month old child.

On presentation, she was in obvious distress and complaining of chest pain. She denied shortness of breath or any other symptoms. She denied any prior symptoms. On examination, she was found to be tachycardic, her blood pressure was normal and review of all other systems was negative.

Her electrocardiogram showed sinus rhythm and was within normal limits. The first troponin was elevated at 0.40 and the second was 0.29 . All other labs were within normal limits.

CT angiography revealed no evidence of pulmonary embolism; however, four tiny metal objects consistent with fractured struts from an IVC filter were identified in the heart, left and right pulmonary arteries, and upper abdomen.

Records obtained from another hospital revealed that a Bard Recovery IVC filter (Bard Peripheral Vascular, Tempe, Arizona) was placed in the course of treating a life-threatening multiple trauma from a motor vehicle accident eight years previously. The patient apparently was in coma for a month and was unaware of the existence of the IVC filter.
C Biomed Central

(c) 2014 Shennib et al.; licensee BioMed Central Ltd. This is an Open Access article distributed under the terms of the Creative Commons Attribution License (http://creativecommons.org/licenses/by/4.0), which permits unrestricted use, distribution, and reproduction in any medium, provided the original work is properly credited. The Creative Commons Public Domain Dedication waiver (http://creativecommons.org/publicdomain/zero/1.0/) applies to the data made available in this article, unless otherwise stated. 
The first strut was protruding inferiorly through the free wall of the right ventricle and was associated with a small pericardial effusion (Figure 1). Two were found in the subsegmental branches of the pulmonary arteries of the left and right lungs. The fourth fragment was found outside the inferior vena cava along the duodenal sweep adjacent to the anterior-inferior margin of the uncinate process (Figure 2). A limb of the remaining structure of the IVC filter was observed to be penetrating into the adjacent abdominal aortic wall superior to the iliac bifurcation.

Initial treatment was limited to in-hospital observation with pain management. However, the pain progressed and became intolerable with excruciating left shoulder pain over the ensuing 48 hours. A repeat CT revealed further penetration of the right ventricular strut through the ventricular wall and into the diaphragm with increasing pericardial effusion. Consequently, the patient was taken to the operating room where midline sternotomy and pericardiotomy was performed. Approximately $300 \mathrm{cc}$ of blood was drained from the pericardial space. An intact, $2.5 \mathrm{~cm}$ metal strut was found protruding from the free wall of the right ventricle and was removed (Figure 3). The small laceration was repaired with a pledgeted 4-0 proline horizontal mattress suture. No cardiopulmonary bypass was needed.

The patient tolerated the procedure well and had immediate relief of her preoperative pain. She had an uneventful recovery and was discharged 3 days postoperatively. At a 3 month follow up appointment, the patient was doing well and had no symptoms. The patient subsequently had

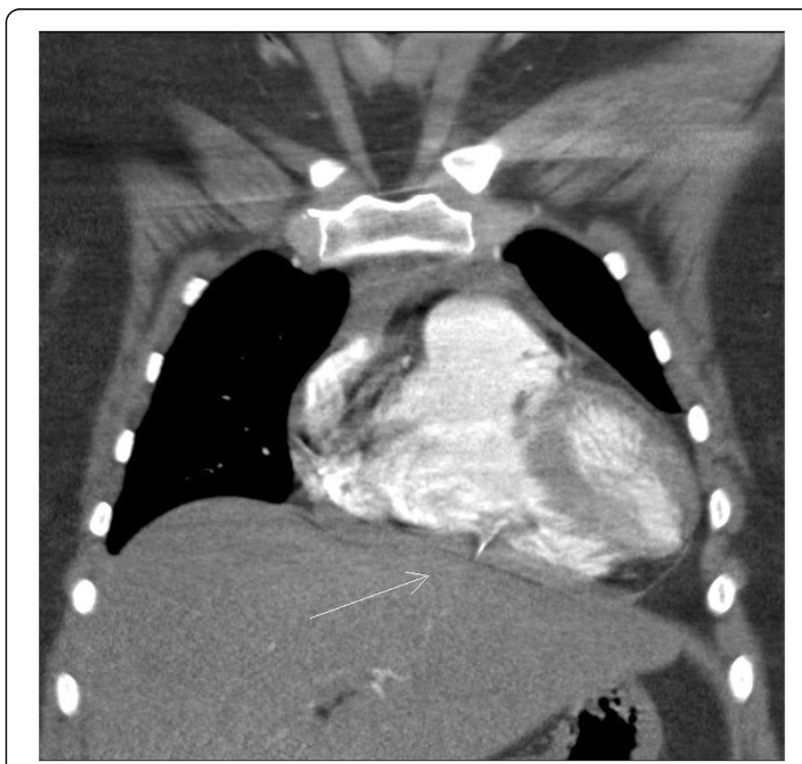

Figure 1 Fractured strut embedded in the right ventricular free wall, protruding into the diaphragm.

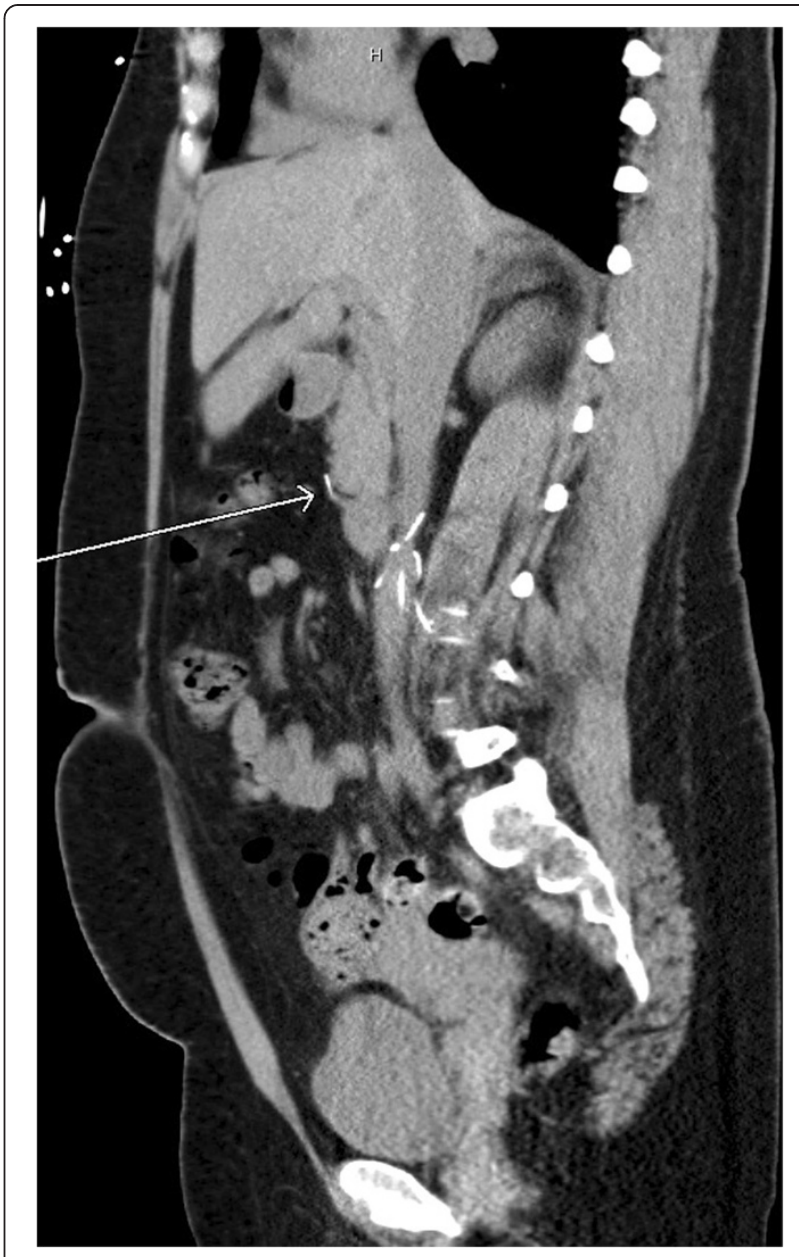

Figure 2 Fractured strut migration near duodenal sweep.

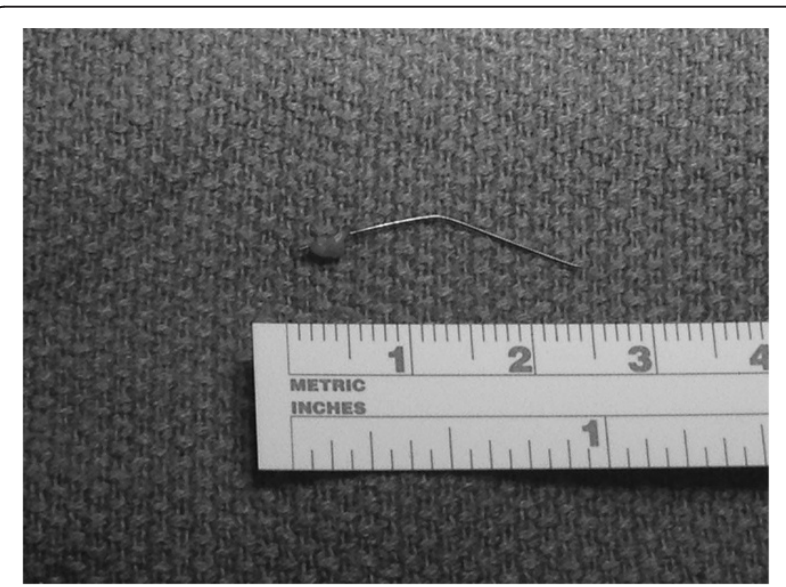

Figure 3 Fractured strut retrieved from right ventricular free wall. 
successful endovascular removal of the main fractured IVC filter.

\section{Conclusions}

There appears to be an expanding use of IVC filters for prevention of pulmonary embolism worldwide [1]. Although IVC filters have been shown to be relatively safe and effective, significant complications have been reported. Fracture and migration is a recognized complication of IVC filter placement, however, patients may not be aware that a filter can fracture and migrate as in the presented case. Activities involving a sudden, intense increase in intra-abdominal pressure have been noted to be frequently associated with filter fracture and migration. Chest pain is the most common presentation. Migration of the complete filter or a fractured segment to the heart or lungs may also manifest with new acute shock and hemodynamic instability.

CT scans of the chest appear to be the most suited radiologic modality for identifying migrated fragments of an IVC filter within the chest. Correlation between chest pain and the location of migrated struts can assist in making management decisions. Increasing chest and shoulder pain with progression of pericardial effusion warrants intervention. Radiologic evaluation of the location and depth of penetration of the strut within the right ventricle may assist in determining if an endovascular or open surgical approach is more appropriate.

Our patient presented with chest pain that was initially controlled pharmacologically. She was hemodynamically stable; however, we observed increasing chest pain and progression of the pericardial effusion, which justified intervention. A less-invasive endovascular retrieval would have been preferred, but the fractured strut appeared to be advancing further into the ventricular free wall and diaphragm, making the retrieval more technically challenging. Because our patient was young and otherwise in good health, open surgery was chosen as a definitive method for the strut retrieval, cardiac defect repair and effusion drainage.

There is a paucity of studies addressing the optimal management of patients with migrating struts from fractured IVC filters. A review of the literature revealed only eight case reports [2-9] clearly documenting IVC filter fragment migration to the right ventricle. A variety of treatment options ranging from conservative pain management to endovascular or open surgical extraction of the migrating struts have been suggested. However, no clear recommendations have been proposed as to the optimal modality. Cardiovascular surgeons need to be aware of the increasing prevalence of IVC filters and the risk of fracture and migration to the right ventricle. Further studies and guidelines are needed to appropriately manage this complication.

\section{Consent}

Informed consent was obtained from the patient for publication of this Case report and any accompanying images. A copy of the written consent is available for review by the Editor-in-Chief of this journal.

\section{Abbreviations \\ IVC: Inferior vena cava.}

\section{Competing interests}

The authors declare that they have no competing interests.

\section{Authors' contributions}

BB carried out the literature review, gathered imaging and drafted the manuscript. $\mathrm{KH}$ participated in the design of the study and helped to draft the manuscript. HS conceived of the case report, participated in its design, and helped to draft the manuscript. All authors read and approved the final manuscript.

\section{Author details}

${ }^{1}$ Arizona Heart Hospital, 1930 East Thomas Road, Phoenix, AZ 85016, USA. ${ }^{2}$ University of Arizona, College of Medicine - Phoenix, 550 East Van Buren Street, Phoenix, AZ 85004, USA.

Received: 17 September 2014 Accepted: 18 November 2014

Published online: 14 December 2014

\section{References}

1. Kuy S, Dua A, Lee CJ, Patel B, Desai S, Dua A, Szabo A, Patel PJ: National trends in utilization of IVC filters over a decade in the United States. J Vasc Surg 2013, 57(5):73S-74S.

2. Baik P, Fourzali R, Salsamendi J, Salerno T: Transventricular migration of an inferior vena cava filter limb. Ann Thorac Surg 2014, 97(1):343.

3. Chandra PA, Nwokolo C, Chuprun D, Chandra AB: Cardiac tamponade caused by fracture and migration of inferior vena cava filter. South Med J 2008, 101(11):1163-1164.

4. Hull JE, Han J, Giessel GM: Retrieval of the recovery filter after arm perforation, fracture, and migration to the right ventricle. J Vasc Interv Radiol 2008, 19(7):1107-1111.

5. Kalavakunta JK, Thomas CS, Gupta V: A needle through the heart: rare complication of inferior vena caval filters. J Invasive Cardiol 2009, 21(11):E221-E223.

6. Kumar SP, Mahtabifard A, Young JN: Fractured inferior vena cava filter strut presenting as a penetrating foreign body in the right ventricle: report of a case. J Card Surg 2008, 23(4):378-381.

7. Rogers NA, Nguyen L, Minniefield NE, Jessen ME, de Lemos JA: Fracture and embolization of an inferior vena cava filter strut leading to cardiac tamponade. Circulation 2009, 119(18):2535-2536.

8. Saeed I, Garcia M, McNicholas K: Right ventricular migration of a recovery IVC filter's fractured wire with subsequent pericardial tamponade. Cardiovasc Intervent Radiol 2006, 29(4):685-686.

9. Tam MD, Spain J, Lieber M, Geisinger M, Sands MJ, Wang W: Fracture and distant migration of the Bard Recovery filter: a retrospective review of 363 implantations for potentially life-threatening complications. J VasC Interv Radiol 2012, 23(2):199-205.e1. 